\title{
Stress-induced analgesia: Time course of pain reflex alterations following cold water swims
}

\author{
RICHARD J. BODNAR, DENNIS D. KELLY, and MURRAY GLUSMAN \\ Department of Behavioral Physiology, New York State Psychiatric Institute \\ and Department of Psychiatry, Columbia University, New York, New York 10032
}

\begin{abstract}
Recent reports indicate that rats acutely stressed by inescapable footshock, rotation, restraint, or injections of hypertonic saline display increased tail-flick latencies. The present study parametrically analyzed the time course of analgesia following exposure to another stressor, a brief, forced cold water swim, by means of three nociceptive reflex tests. Rats acutely subjected to a cold water $\left(2^{\circ} \mathrm{C}\right)$ swim for $3.5 \mathrm{~min}$ displayed significantly elevated tail-pinch and flinch-jump thresholds for up to $60 \mathrm{~min}$; no change was noted in similarly treated warm water $\left(28^{\circ} \mathrm{C}\right)$ controls. Tail-flick withdrawal latencies to radiant heat stimuli exhibited similar, but more enduring, increases, lasting up to $120 \mathrm{~min}$. These results demonstrate that reactivity to three different nociceptive reflex modalities, electric shock, heat, and pressure, can be altered by acute exposure to a stressor.
\end{abstract}

Converging lines of evidence from recent neurochemical, electrophysiological, and behavioral studies (Mayer \& Price, 1976) suggest the existence of a phylogenetically ancient brain system whose function is to modulate or inhibit sensitivity to painful stimuli. It is likely that such a neural pain-relief system evolved and apparently survived because it offered a significant selective advantage to its possessors. There are many conceivable instances in which an organism's normal reactions to painful stimuli, prompting withdrawal, rest, and other recuperative behaviors, could be seriously disadvantageous, such as during predation, defense, intraspecific confrontations for dominance, and acute adaptation to extreme environmental demands. It has been known since the classic studies of Cannon (1939) that the response to noxious or threatening stimuli is one of the basic adaptive mechanisms of animals and man. Emergency situations are met with a number of autonomic adjustments of varying durations, such as changes in heart rate, muscle vasodilation, pupillary dilation, glucose and fat mobilization, constriction of capillary beds in the skin, and altered respiration, as well as a complex, but integrated neuroendocrine response, involving pituitary-adrenal and sympathomedullary activation (Selye, 1952).

Recent experiments suggest that another important component of the emergency response seen in the response to stress may be a reduction in sensitivity

The research was supported by National Institute of Mental Health Grant 13579 to Murray Glusman and New York State Health Research Council Grants 922 to Richard J. Bodnar and 365 to Dennis Kelly. We thank A. Spiaggia and L. Skaredoff for technical assistance. Requests for reprints should be sent to R. J. Bodnar, Department of Behavioral Physiology, New York State Psychiatric Institute, 722 W. 168th Street, New York, New York 10032. to painful events. The initial observation (Hayes, Bennett, Newlon, \& Mayer, 1976) that rats displayed increased tail-flick latencies following acute exposure to such severe stressors as inescapable footshock, rotation, or intraperitoneal injections of hypertonic saline has generated further research into the analgesic mechanisms underlying those stressors (Akil, Madden, Patrick, \& Barchas, 1976, pp. 63-70; Chance, White, Krynock, \& Rosecrans, 1977; Madden, Akil, Patrick, \& Barchas, 1977; Rosecrans \& Chance, 1976) and into extending the types of stressful events that induce analgesia (Spiaggia, Bodnar, Kelly, McManus, \& Glusman, 1977; Bodnar, Brutus, Glusman, \& Kelly, Note 1).

The present study investigated the analgesic time course of another severe environmental stressor, exposure to cold water swims, upon three different nociceptive reflex mechanisms examined in separate sets of subjects: reactivity to electric shock, heat, and pressure.

\section{METHOD}

\section{Flinch-Jump Thresholds}

Forty-eight naive male albino Holtzman Sprague-Dawley rats $(350-500 \mathrm{~g})$ were tested for flinch-jump thresholds in a standard chamber with a $30 \times 24 \mathrm{~cm}$ grid floor composed of 14 grid bars $(.6-\mathrm{cm}$ diam) spaced $1.8 \mathrm{~cm}$ apart. Scrambled electric shocks were delivered through the grids by a constantcurrent shock generator. Using an ascending method of limits of successively more intense shocks (Evans, 1961), the flinch threshold was defined in milliamperes as the lowest intensity that elicited a withdrawal of a single paw from the grids. The initial jump threshold was defined as the lowest intensity that elicited simultaneous withdrawal of both hindpaws from the grids. The jump threshold was defined as the lowest of two consecutive intensities that elicited a jump as above. Each trial began with the animal receiving a 300 -msec footshock at a current intensity of $.1 \mathrm{~mA}$. Subsequent shocks were increased 
in equal $.05-\mathrm{mA}$ steps at 20 -sec intervals. Following the determination of flinch, initial jump, and jump thresholds on each trial, the current intensity was reset to $.1 \mathrm{~mA}$ for the next trial until 10 trials were completed.

After 3 days of stable baseline thresholds, animals were exposed to either a cold water stress or a warm water control bath. In the cold water stress condition, each animal was placed in a bath of $2^{\circ} \mathrm{C}$ ice water and forced to swim for $3.5 \mathrm{~min}$. The water was too deep for the animal to stand without being submerged. The warm water control condition was identical to the cold water condition, except the water temperature was $28^{\circ} \mathrm{C}$. Following exposure to either the cold water or warm water condition, flinch, initial jump, and jump thresholds were determined at one of four postswim intervals: $30,60,120$, or $240 \mathrm{~min}$. Additionally, for all subjects, the same thresholds were redetermined $24 \mathrm{~h}$ after the swim. Between swim exposure and psychophysical testing, the rats were placed in individual cages lined with newspaper. In all, there were eight groups of six animals each: a cold water stress group and a warm water control group at each of the four postswim intervals.

\section{Tail-Flick Latencies}

Six additional naive male rats were tested on tail-flick withdrawal using the procedure of D'Amour and Smith (1941). A radiant heat source was mounted $1.3 \mathrm{~cm}$ above the tail of the restrained animal, and a thermal stimulus was applied to the dorsum of the tail $4 \mathrm{~cm}$ proximal to the tip. The intensity of the thermal stimulus was adjusted to produce a tail-flick latency of between 3 and $6 \mathrm{sec}$. Single trials were scheduled at $15 \mathrm{~min}$ before the cold water swim, immediately prior to the swim, and then at $30,60,120,180$, and $240 \mathrm{~min}$ following the swim. To avoid tissue damage in testing tail-flick latencies, the trials were automatically terminated if a withdrawal response to the heat stimulus did not occur within $9 \mathrm{sec}$.

\section{Tail-Pinch Thresholds}

Seven naive male rats were tested for tail-pinch thresholds in a modification of the method of Randall and Selitto (1957). Linearly increasing pressure delivered by a motor-driven analgesy meter (Ugo-Basile, Milan, Italy) was applied to the tail $8 \mathrm{~cm}$ proximal to the tip until the occurrence of a withdrawal response defined by forelimb and/or hindlimb struggling in the experimenter's grip. Two trials were scheduled before the cold water swim and single trials at $30,60,120$, and $180 \mathrm{~min}$ following the swim. The same sequence of tests surrounding a warm water $\left(28^{\circ} \mathrm{C}\right)$ swim was repeated 1 week later.

\section{RESULTS}

\section{Flinch-Jump Thresholds}

Figure 1 displays the time course of alterations in nociceptive thresholds following the cold water stress and warm water control swims. Both jump thresholds were significantly elevated at $30 \mathrm{~min}$ [correlated $\mathrm{t}$ tests: jump, $\mathrm{t}(5)=10.20, \mathrm{p}<.01$; initial jump, $\mathrm{t}(5)=19.20$, $\mathrm{p}<.01]$ and $60 \mathrm{~min}$ [jump, $\mathrm{t}(5)=4.28, \mathrm{p}<.01$; initial jump, $\mathrm{t}(5)=3.72, \mathrm{p}<.02$ ] following cold water stress, but they returned to normal at $120 \mathrm{~min}, 240 \mathrm{~min}$, and $24 \mathrm{~h}$. In contrast, the warm water control swim failed to produce any significant changes in either jump threshold at any time. Thus at 30 and $60 \mathrm{~min}$, both jump thresholds in the cold water stressed rats were significantly higher than those of the warm water control rats [ANOVA: jump, $F(1,40)=19.67, p<.01$; initial jump, $F(1,40)=16.49, p<.01]$ and significantly higher as compared to later time intervals [jump,

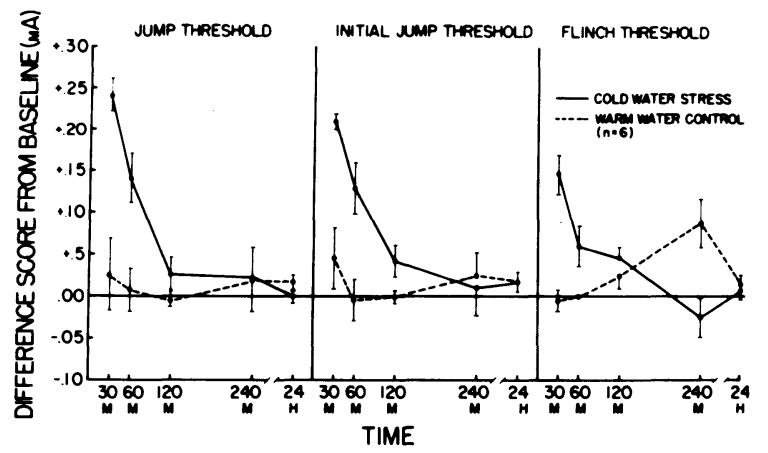

Figure 1. Alterations in flinch-jump thresholds at four intervals following cold water stress and warm water control swims. Each data point represents the mean $( \pm S E)$ of a separate group of six rats.

$F(3,40)=6.60, p<.01 ;$ initial jump, $F(3,40)=6.41$, $\mathrm{p}<.01]$. The flinch-threshold data were somewhat less clear cut, but generally confirmed the two jumpthreshold measures. Flinch thresholds were significantly higher in the $30-\mathrm{min}[\mathrm{t}(5)=5.42, \mathrm{p}<.01]$ and $120-\mathrm{min}$ $[\mathrm{t}(5)=2.87, \mathrm{p}<.05]$ cold water groups, but not at other intervals, nor in any of the warm water control groups except, inexplicably, at $240 \mathrm{~min}[\mathrm{t}(5)=2.57$, $\mathrm{p}<.05]$. Overall flinch-threshold differences were significantly higher in the cold water stress condition than in the warm water condition $[\mathrm{F}(1,40)=12.52$, $\mathrm{p}<.01]$, and there was no significant change in flinch thresholds across the intervals. However, there were significant changes in flinch threshold in the interaction between the experimental condition and the time interval $[F(3,40)=7.72, p<.01]$. As the time interval between swim and footshock test increased, the flinch differences in the cold water condition decreased, while the flinch-threshold differences in the warm water condition increased.

\section{Tail-Flick Latencies}

As summarized in Table 1, tail-flick latencies to radiant heat showed significant increases [ANOVA: $\mathrm{F}(5,36)=9.39, \mathrm{p}<.01]$ for $120 \mathrm{~min}$ following the cold water swim. Latencies returned to baseline levels by $180 \mathrm{~min}$ after the swim.

\section{Tail-Pinch Thresholds}

Table 1 also summarizes the alterations in tail-pinch thresholds following the cold water stress and warm water control conditions. Cold water stress significantly elevated tail-pinch thresholds [ANOVA: $F(4,30)=15.65$, $\mathrm{p}<.01] 30$ and $60 \mathrm{~min}$ later, whereas thresholds following the warm water control condition were unaltered $[\mathrm{F}(3,31)=.41]$.

\section{DISCUSSION}

As measured by three different nociceptive reflex tests, analgesia was apparently produced for more than $1 \mathrm{~h}$ by a single, brief, forced swim in cold water, but not by a similar swim in 
Table 1

Time Course of Alterations in Tail-Flick Latencies $(n=6)$ and Tail-Pinch Thresholds $(n=7)$ Following Cold Water Stress and Warm Water Control Conditions

Tail-Flick Latencies (seconds) Tail-Pinch Thresholds (grams)

\begin{tabular}{|c|c|c|c|c|c|c|c|c|c|c|c|c|c|c|c|}
\hline \multicolumn{7}{|c|}{ Cold Water Stress } & \multicolumn{4}{|c|}{ Cold Water Stress } & \multicolumn{5}{|c|}{ Warm Water Control } \\
\hline & & \multicolumn{5}{|c|}{ Post } & \multicolumn{6}{|c|}{ Post } & \multicolumn{3}{|c|}{ Post } \\
\hline & Pre & 30 & 60 & 120 & 180 & 240 & Pre & 30 & 60 & 120 & 180 & Pre & 30 & 60 & 120 \\
\hline $\begin{array}{l}\text { Mean } \\
F\end{array}$ & 4.85 & $\begin{array}{c}9.00 \\
100.67 *\end{array}$ & $\begin{array}{c}7.63 \\
16.03 *\end{array}$ & $\begin{array}{c}7.01 \\
10.26^{*}\end{array}$ & $\begin{array}{r}4.77 \\
.01\end{array}$ & $\begin{array}{l}5.55 \\
2.19\end{array}$ & 213.3 & $\begin{array}{l}586.8 \\
51.84^{*}\end{array}$ & $\begin{array}{l}459.9 \\
21.90 *\end{array}$ & $\begin{array}{r}300.9 \\
3.96\end{array}$ & $\begin{array}{r}276.9 \\
1.88\end{array}$ & 275.7 & $\begin{array}{r}325.2 \\
.89\end{array}$ & $\begin{array}{r}271.8 \\
0.0\end{array}$ & $\begin{array}{r}287.1 \\
0.0\end{array}$ \\
\hline
\end{tabular}

${ }^{*} p<.01$; all other values were nonsignificant.

warm water. In the flinch-jump test, jump thresholds consistently manifested a 60 -min analgesic time course following the cold water stress; flinch thresholds appeared less reliable. While tail-pinch thresholds displayed a similar analgesic time course to flinch-jump thresholds, tail-flick latencies showed longer, more persistent nociceptive elevations. The analgesia that followed the cold water swims was clearly not produced by such factors as wet fur, immersion in water, swimming, or exercise, since the nonanalgesic warm water control subjects were exposed to identical factors. The time course of stressinduced analgesia in the present study is in rough agreement with the Akil et al. (1976) data concerning alterations in tail-flick latencies following a 1-h exposure to repeated footshock. Further, the time course of the analgesia produced by the cold water swim is similar to the time course of avoidance learning deficits found by Seligman and others (Maier, Albin, \& Testa, 1973; Overmier \& Seligman, 1967; Seligman \& Maier, 1967) and by Weiss (Glazer, Weiss, Pohorecky, \& Miller, 1975; Weiss \& Glazer, 1975; Weiss, Glazer, Pohorecky, Brick, \& Miller, 1975) following exposure to such stressful situations as repeated unavoidable shocks or a cold water swim identical to that employed here. Seligman attributed these avoidance learning deficits to "learned helplessness," that is, the animal's having learned the negative response contingency during the unavoidable shock session in that its responses were ineffective in controlling shock. Alternatively, Weiss attributed the avoidance learning deficits to a deficiency in motor activation caused by norepinephrine depletion during exposure to the stressor. The present study suggests that stress-induced analgesia, as measured by increases in respondent nociceptive thresholds, may also contribute to the apparent avoidance learning deficits previously noted by Seligman and Weiss.

Finally, the phenomenon of stress-induced analgesia would appear to have serious implications for the widespread practice of measuring analgesia by administering a battery of different nociceptive tests in close succession. While this experimental design may help establish the generality of alterations in pain sensitivity, such stressors as electric footshock and ice baths have of ten been used as noxious stimuli in these tests. In such cases the nociceptive test itself may be stressful and thus bias subsequent tests. Therefore, if multiple measures of nociception are to be performed in the same animal during the same test session, the possibility of serious interactions across tests exists unless the intervals between tests exceed the maximum duration of stress-induced threshold alterations ( $2 \mathrm{~h}$ in the present study) or unless the subjects have been previously adapted to the multiple test battery for at least 1-2 weeks, the normal time course of adaptation for stress-induced analgesia (Bodnar, Kelly, Spiaggia, \& Glusman, 1978). We would therefore recommend that if a multiple nociceptive test design is to be used, either animals be tested in separate groups on the different tests or a counterbalanced design be employed to determine the extent and nature of the analgesic interactions produced by stress.

\section{REFERENCE NOTE}

1. Bodnar, R. J., Brutus, M., Glusman, M., \& Kelly, D. D. Analgesia induced by 2-deoxy-D-glucose, an antimetabolic glucose analogue. Manuscript submitted for publication, 1978.

\section{REFERENCES}

Akil, H., Madden, J., Patrick, R. L., \& Barchas, J. D. Stress-induced increase in endogenous opiate peptides: Concurrent analgesia and its partial reversal by naloxone. In H. W. Kosterlitz (Ed.), Opiates and endogenous opioid peptides. Amsterdam, North Holland: 1976.

Bodnar, R. J., Kelly, D. D., Spiaggia, A., \& Glusman, M. Stress-induced analgesia: Adaptation following chronic cold water swims. Bulletin of the Psychonomic Society, $1978,11,337-340$.

Cannon, W. B. The wisdom of the body. New York: Norton, 1939.

Chance, W. T., White, A. C., Krynock, G. M., \& Rosecrans, J. A. Centrifugal control of nociception: Autoanalgesic mechanisms. Society for Neuroscience Abstracts, 1977, 3, 479.

D'Amour, F. E., \& Smith, D. L. A method for determining loss of pain sensation. Journal of Pharmacology and Experimental Therapeutics, 1941, 72, 74-79.

Evans, W. O. A new technique for the investigation of some analgesic drugs on a reflexive behavior in the rat. Psychopharmacology, 1961, 2, 318-325.

Glazer, H. I., Weiss, J. M., Pohorecky, L. A., \& Miller, N. E. Monoamines as mediators of avoidance-escape behavior. Psychomatic Medicine, 1975, 37, 535-543.

hayes, R. L., Bennett, G. J., Newlon, P., \& Mayer, D. J. Analgesic effects of certain noxious and stressful manipulations in the rat. Society for Neuroscience Abstracts, 1976, 2, 1350.

Madden, J., Akil, H., Patrick, R. L., \& Barchas, J. D. Stress-induced parallel changes in central opioid levels and pain responsiveness in the rat. Nature, 1977, 265, 358-360.

Maier, S. F., Albin, R. W., \& Testa, T. J. Failure to learn to escape in rats previously exposed to inescapable shock depends on nature of escape response. Journal of Comparative and Physiological Psychology, 1973, 85, 581-592.

MaYer, D. J., \& Price, D. D. Central nervous system mechanisms of analgesia. Pain, 1976, 2, 379-404.

Overmier, J. B., \& Seligman, M. E. P. Effects of inescapable shock upon subsequent escape and avoidance learning. Journal of Comparative and Physiological Psychology, 1967, 63, 28-33.

Randall, L. O., \& Selitto, J. J. A method for measurement of analgesic activity on inflamed tissue. Archives of International Pharmacodynamics, 1957, 11, 409.

Rosecrans, J. A., \& Chañce, W. T. Emotionality-induced antinociception. Society for Neuroscience Abstracts, 1976, 2, 919. 
Seligman, M. E. P., \& Maier, S. F. Failure to escape traumatic shock. Journal of Experimental Psychology, $1967,74,1-9$.

SELYE, H. The story of the adaptation syndrome. Montreal: Acta, 1952.

Spiaggia, A., Bodnar, R. J., Kelly, D. D., McManus, M. E., \& Glusman, M. Biphasic alterations in nociceptive thresholds after food deprivation. Society for Neuroscience Abstracts, 1977, 3, 492.
Weiss, J. M., \& Glazer. H. I. Effects of acute exposure to stressors on subsequent avoidance-escape behavior. Psychosomatic Medicine, 1975, 37, 499-521.

Weiss, J. M., Glazer, H. I., Pohorecky, L. A., Brick, J., \& Miller, N. E. Effects of chronic exposure to stressors on avoidance-escape behavior and on brain norepinephrine. Psychosomatic Medicine, 1975, 37, 522-534.

(Received for publication January 20, 1978.) 